\title{
Desain dan Pembuatan Cetakan Papan Tiruan Metode Cetak Tekan
}

\section{Design and Manufacture of Artificial Boards From Laminate Composite Materials Reinforced by Banana Stem Sheets}

\author{
Christoper Hutasoit ${ }^{*}$, Frawito T.S. Sihombing ${ }^{2}$, Trio Ismanto Padang ${ }^{3}$ \\ 1,2,3 Jurusan Teknik Mesin, Fakultas Teknologi Industri, Institut teknologi Medan, Indonesia \\ Diterima: 17-08-2020 ; Disetujui: 14-02-2021 ; Diterbitkan: 06-05-2021 \\ *Corresponding author: chris26.ch12@gmail.com
}

\begin{abstract}
Abstrak
Peningkatan kebutuhan kayu untuk keperluan papan dan lain-lain mendorong dilakukannya penyelidikan untuk membuat kayu dari bahan lain yang melimpah dan ramah lingkungan. Kerusakan hutan menyebabkan penggunaan kayu dari hutan dibatasi sehingga mendorong kegiatan penyelidikan untuk mendapatkan kayu tiruan dari bahan alami. Wilayah Indonesia merupakan daerah yang subur ditanami oleh tanaman pisang sehingga jenis tanaman ini dijumpai dalam jumlah yang cukup banyak. Oleh karena itu, diperlukan alat untuk membuat kayu tiruan yang dapat digunakan secara dengan mudah dan murah.Tujuan studi ini ialah untuk merancang dan membangun alat cetak kayu tiruan dari bahan pelepah batang pisang. Metode yang digunakan ialah metode tekan dengan ketebalan $50 \mathrm{~mm}$. Bahanbahan yang digunakan berasal dari bahan-bahan yang mudah dijumpai dengan harga yang relatif lebih murah. Analisa kekuatan alat menggunakan perhitungan kesetimbangan gaya statis dari hukum-hukum gerak mekanik Newton. Hasilnya diperoleh alat cetak kayu tiruan dengan sumber beban berasal dari pompa hidrolik sederhana. Alat ini juga telah berhasil menghasilkan papan tiruan dari bahan komposit laminate pelepah pisang
\end{abstract}

Kata Kunci: Cetakan Papan Tiruan, Komposit Laminate, Metode Tekan

\begin{abstract}
At present, the use of agricultural waste materials that are environmentally friendly and easily biodegradable in nature is a major priority in developing alternative materials for engineering. Indonesia is the largest producer of banana products and has the potential to produce abundant banana stem waste in every harvest. In this study, the objective of the investigation was to design artificial boards from waste banana stalks, print them into dummy boards, and test their mechanical strength. The product design is based on a commercial board thickness of $50 \mathrm{~mm}$. Making artificial boards using a special molding method using the press method. Testing of flexural strength using the Universal Testing Machine with the threepoint bending method. The result is that the artificial board has an additional thickness of $10 \%$ from the initial thickness due to the characteristic of banana stems which have air cavities. When compared with commercial boards, the resulting artificial board has a fairly good damping ability against a given load so that further investigation is needed for the development of this material to produce a better board quality. Keywords: Artificial board, banana stem, laminate composite
\end{abstract}

How to Cite: Hutasoit, C. 2021, Desain dan Pembuatan Cetakan Papan Tiruan Metode Cetak Tekan, JMEMME (Journal of Mechanical Engineering, Manufactures, Materials and Energy), Vol 5 (1): 8-17 


\section{PENDAHULUAN}

Pada saat ini, kebutuhan bahan baku kayu di Indonesia untuk keperluan industri telah melampaui kemampuan sumber daya alam yang ada. Salah satu penyebabnya ialah meningkatnya pertumbuhan industri kayu sehingga menyebabkan terjadi defisit kayu [1]. Selain itu, peningkatan jumlah penduduk menyebabkan peningkatan juga akan kebutuhan papan masyarakat. Pada tahun 2013, kebutuhan logistik nasional tercatat hingga mencapai 49 juta m3 [2]. Kebutuhan itu dipenuhi dari hutan alam sebesar 4 juta $\mathrm{m} 3$, perhutani sebesar 922,123 m3 , hutan tanaman industri sebanyak 21 juta m3. Untuk sisa kebtuhan kayu tersebut dipenuhi dari hutan rakyat dengan suplai sebanyak 23 juta m3 [3].

Hutan rakyat merupakan salah satu alternatif untuk mengatasi kekurangan kebutuhan kayu sekarang dan di masa depan tentunya [4]. Pengembangan hutan rakyat di arahkan untuk mengembalikan produktivitas lahan kritis, konservasi lahan, perlindungan hutan, dan penuntasan kemiskinan melalui pemberdayaan masyarakat. Berdasarkan data Direktorat Jendral BPDAS dan perhutanan Sosial tahun 2013, perkembangan hutan rakyat di Indonesia tahun 2012 mencapai hingga 1.119.937 ha [5].

Produksi tanaman pisang di Indonesia cukup besar, bahkan Indonesia telah menjadi salah satu penghasil pisang terbesar di dunia. Berdasarkan angkat tetap (ATAP) tahun 2013 produksi pisang mencapai 6,28 juta ton [6]. Untuk wilayah Asia, 50\% produksi pisang dihasilkan dari Indonesia. Hampir seluruh wilayah Indonesia merupakan daerah penghasil pisang karena didukung oleh iklim yang sesuai. Pengembangan dan persebaran pisang dipengaruhi oleh beberapa faktor, antara lain iklim, media tanam dan ketinggian tempat. Namun demikian $90 \%$ produksi pisang masih digunakan untuk konsumsi dalam negeri, sedang kan untuk ekspor hanya 10\% [7].

Kayu adalah suatu bahan karbohidrat yang tersusun terutama atas karbon, hidrogen dan oksigen [8]. Kayu mengandung senyawa organik yang tetap tinggal (residu) setelah terjadi pembakaran pada suhu tinggi pada kondisi oksigen yang melimpah yang dikenal sebagai abu. Unsur-unsur penyusun kayu tergabung dalam sejumlah senyawa organik yaitu : selulosa, hemiselulosa dan lignin.

Bahan komposit (composite) adalah suatu jenis bahan baru hasil rekayasa yang terdiri dari dua atau lebih bahan dimana sifat masing-masing bahan berbeda satu sama lainnya baik itu sifat kimia maupun fisiknya dan tetap terpisah dalam hasil akhir bahan tersebut [9]. Sifat-sifat bahan penyusun tersebut berbeda bentuk dan komposisi kimia. Pendapat lain mengatakan bahwa komposit adalah sebuah kombinasi material yang berfasa padat yang terdiri dari dua atau lebih material secara skala makroskopik yang mempunyai kualitas lebih baik dari material pembentuknya [10] [11]. Material komposit yang banyak dipergunakan saat ini merupakan material non logam. Hal ini disebabkan material ini memiliki keunggulan berat jenis yang lebih ringan dan bahan baku yang tersedia banyak di alam [12]. Selain itu material ini diprioritaskan pada sifat lain yang lebih baik, yaitu tahan korosi dan ramah lingkungan [13]. Selain itu, teknologi merupakan salah satu sifat yang harus dimiliki dalam memproduksi material komposit tersebut [14]. 
Bahan komposit telah digunakan dalam industri pesawat terbang, otomotif, maupun alat-alat olahraga. Penggunaan komposit di berbagai bidang tidak lepas dari sifat-sifat unggul yang dimiliki komposit yaitu, ringan, kuat, kaku, serta tahan terhadap korosi. Pada dasawarsa terakhir kecenderungan pengembangan material komposit bergeser pada serat alam kembali sebagai pengganti serat sintetik. Hal ini didukung oleh beberapa keunggulan yang dimiliki serat alam, diantaranya adalah masa jenisnya rendah, terbarukan, produksi memerlukan energi yang rendah, proses lebih ramah lingkungan, serta memiliki sifat insulasi panas dan akustik yang baik.

Penggunaan serat alam juga dipicu oleh adanya regulasi tentang persyaratan habis pakai produk komponen otomotif bagi negara-negara Uni Eropa dan Asia [15]. Sejak tahun 2006 negara-negara Uni Eropa telah mendaur ulang 80 \% komponen otomotif dan akan meningkatkan menjadi 85 \% pada tahun 2015. Di Asia khususnya Jepang, pada tahun 2005 sekitar 88 \% komponen otomotif telah di daur ulang.

Pertimbangan pemilihan serat untuk komposit sangat dipengaruhi oleh beberapa parameter diantaranya adalah nilai kekuatan dan kekakuan komposit yang diinginkan, perpanjangan ketika patah, stabilitas termal, ikatan antara serat dan matrik, perilaku dinamik, perilaku jangka panjang, massa jenis, harga, biaya proses, ketersediaan dan kemudahan daur ulang [16]. Selain itu pemakaian serat alam dari tanaman yang berumur relatif pendek seperti rami dan kenaf dapat mengurangi pemakaian kayu sehingga dapat membantu mengurangi laju kerusakan hutan.

Komposit sandwich merupakan jenis komposit yang cocok untuk menahan beban lentur, Impact, meredan getaran, dan suara [17]. Komposit sandwich dibuat untuk mendapatkan struktur yang ringan tetapi memiliki kekakuan dan kekuatan yang tinggi. Biasanya pemilihan bahan untuk komposit sandwich, syaratnya adalah ringan tahan panas dan korosi, serta harga juga dipertimbangkan. Dengan menggunakan material inti yang sangat ringan, maka akan menghasilkan komposit yang mempunyai sifat kuat, ringan dan kaku. Komposit sandwich dapat di aplikasikan sebagai struktural maupun non-struktural bagian internal dan eksternal pada kereta, bus, truk, dan jenis kendaraan yang lainnnya. Sandwich memberikan insulasi termal dan dapat memenuhi fungsin struktur primer [18].

Beberapa ahli telah mendefinisikan pengertian tentang desain produk. Adapun pengertian dari desain produk menurut Suyadi Prawirosentono dalam bukunya Manajemen Produksi ialah desain produk merupakan rancang bangun dari suatu produk (barang) yang akan diproduksi [19]. Franklin G Moore dan Thomas E Hederick dalam bukunya Manajemen Produksi dan Operasi mengatakan bahwa desain produk merupakan hal yang paling penting, karena kesempatan yang dimiliki produk baru sering menakjubkan. Dimana pada suatu waktu, produk baru dapat menaikkan dua kali atau tiga kali omset suatu organisasi [20]. Berdasarkan beberapa pengertian desain Produk tersebut terlihat bahwa desain produk mempunyai maksud dan tujuan untuk membantu perusahaan dalam menciptakan dan mengembangkan produk baru atau untuk menjamin hasil produksi yang sesuai dengan keinginan pelanggan disatu pihak serta dipihak lain untuk menyesuaikan dengan kemampuan perusahaan. 
Beberapa penyelidikan pada bahan komposit telah dikerjakan dan dilaporkan. Penyelidikan-penyelidikan tersebut antara lain: pembuatan bahan busa dari serat tandan kosong kelapa sawit [21], pembuatan papan skateboard dari batang pisang [17], pembuatan pipa air dari arang kayu [22], pembuatan pipa air dari kulit kerang [20], dll. Selain itu, penyelidikan bahan-bahan ini juga termasuk analisa kekuatannya secara numerical berdasarkan hasil eskperimen sehingga diperoleh kondisi pembebanan secara detail [23] [24] [25] [26].

Penyelidikan ini bertujuan untuk merancang dan membangun alat pembuat kayu tiruan dengan menggunakan metode tekan. Jenis bahan yang digunakan ialah komposit laminate pelepah pisang yang telah diberi perlakuan awal dan disusun berdasarkan bentuk dan ukuran kayu komersil.

\section{METODE PENELITIAN}

Penyelidikan dilaksanakan di Laboratorium Proses Produksi, Jurusan Teknik Mesin, Institut Teknologi Medan, Indonesia. Bahan-bahan yang dipergunakan antara lain plat baja AISI 1040, plat siku ukuran profil 50 x $50 \mathrm{~mm}$, besi hollow ukuran profil 50 x $50 \mathrm{~mm}$, kawat las, dan cat pelapis. Alat-alat yang dipergunakan antara lain mesin las listrik, mesin potong batang besi, mesin gerinda tangan, dan ragum.

Desain cetakan didasarkan pada bentuk dan ukuran asli papan komersial yang akan ditiru, yaitu kayu profil berukuran penampang 50 x $20 \mathrm{~mm}$. Panjang kayu yang akan dibentuk untuk pada penelitian awal ini ialah sepanjang $300 \mathrm{~mm}$. Prosedur pembuatan cetakan papan tiruan tersebut adalah sebagai berikut: (1) potong plat $2 \mathrm{~mm}$ dengan ukuran $300 \mathrm{~mm}$ x $200 \mathrm{~mm}$ sebanyak 2 buah, (2) potong plat siku dengan ukuran $300 \mathrm{~mm}$ sebanyak 2 buah, (3) potong plat siku dengan ukuran $200 \mathrm{~mm}$ sebanyak 2 buah, (4) las plat siku pada sisi-sisi dengan ukuran panjang yang sesuai, (5) rangkai dongkrak, tiang penekan, batang penekan serta plat penekan sesuai sketsa yang ditetapkan sebelumnya.

\section{HASIL DAN PEMBAHASAN}

Wadah cetakan kayu tiruan terdiri dari: (a) plat dasar wadah cetakan dari plat baja $5 \mathrm{~mm}$, (b) plat dinding wadah dari plat baja $5 \mathrm{~mm}$, dan (c) batang hollow $50 \times 20 \mathrm{~mm}$. Bentuk wadah yang telah dirakit diperlihatkan pada gambar 1.

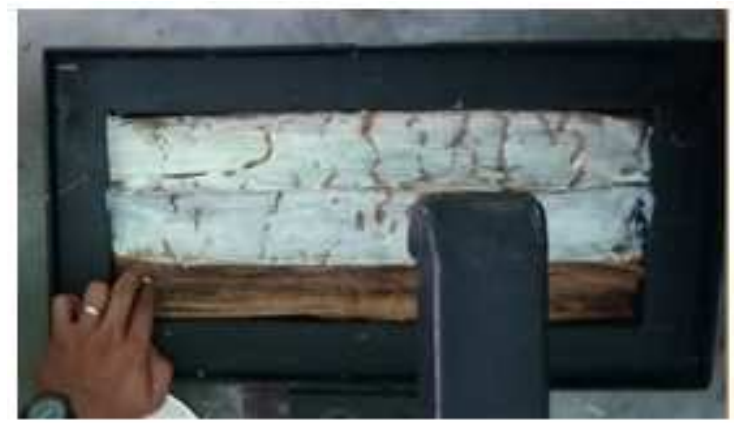

Gambar 1. bentuk wadah yang telah dirakit 
Pembuatan lengan tekan didasarkan pada analisa statika struktur dengan menggunakan persamaan ressultan gaya dan momen pada batang. Berdasarkan persamaan (2.5), panjang lengan yang dibutuhkan untuk mendapatkan tekanan yang $2 \mathrm{x}$ lebih besar dari tekanan yang diberikan oleh bagian hidraulik ialah $600 \mathrm{~mm}$. Jarak antara ujung lengan penekan dengan titik tumpuan pin ialah $400 \mathrm{~mm}$. Sementara jarak antara ujung penekan plat tekan dan titik tumpuan pin ialah $200 \mathrm{~mm}$. Bentuk lengan tekan diperlihatkan pada gambar 2 .

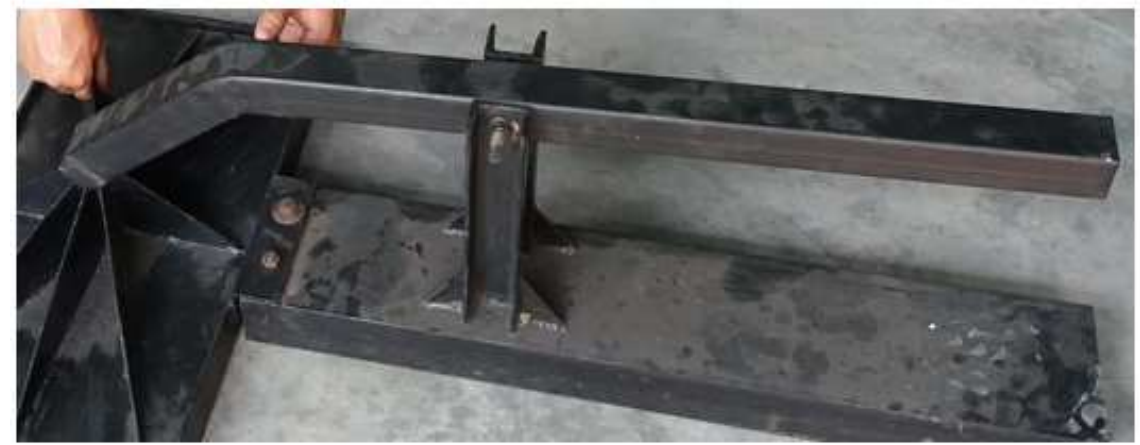

Gambar 2. Mekanisme lengan penekan

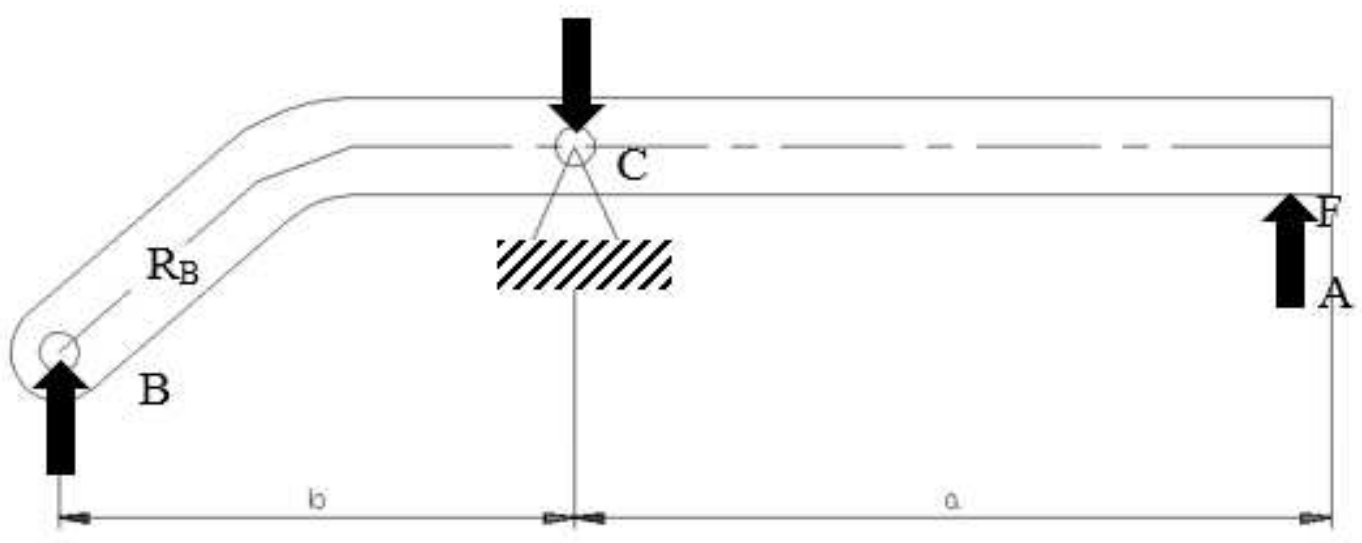

Gambar 3. Diagram benda bebas lengan penekan

Titik $\mathrm{C}$ adalah titik tumpuan lengan penekan. Besarnya gaya tekan dihasilkan dari gaya reaksi pada titik $\mathrm{B}(\mathrm{RB}\urcorner)$ akibat gaya $\mathrm{F}$ yang diberikan pada titik A. Dengan menganggap gaya yang diberikan pada titik A adalah gaya statik, maka resultan gaya dan momen yang terjadi pada batang penekan diasumsikan nol. Oleh karena itu, agar $\mathrm{RB}=2 \mathrm{~F}$, maka panjang lengan a dan $\mathrm{b}$ memiliki persamaan $\mathrm{a}=2 \mathrm{~b}$. Panjang lengan penekan ialah $\mathrm{L}$ $=600 \mathrm{~mm}$, oleh karena itu panjang lengan b ialah sebesar $200 \mathrm{~mm}$. Dengan demikian panjang titik B ke tumpuan $\mathrm{C}$ ialah $\mathrm{a}=\mathrm{L}-\mathrm{b}=600-200=400 \mathrm{~mm}$.

Mekanisme Penekan Plat Tekan (Lengan Tekan) ini tebuat dari baja hollow tube. Dari uji tarik profil Hollow Tube yang dilakukan di laboratorium didapatkan nilai tengangan putus $(\mathrm{fu})=3240 \mathrm{~kg} / \mathrm{cm} 2$ dan tegangan leleh $(\mathrm{fy})=2700 \mathrm{~kg} / \mathrm{cm} 2$. Sedangkan gaya yang bekerja pada titik A yang diterima dari dongkrak adalah 1362,587 Newton 
$(138,945 \mathrm{~kg})$. Maka dapat disimpulkan bahwa mekanisme penekan plat tekan (lengan Tekan) mampu menyalurkan gaya dari titik A ke B.

Alat ini dilengkapi dengan bagian penekan kayu. Bagian ini berfungsi untuk memadatkan lapisan-lapisan bahan baku kayu tiruan yang telah disusun di dalam wadah cetakan kayu tiruan. Selain itu bagian ini juga berfungsi untuk meratakan permukaan papan yang dicetak. Dengan demikian bentuk papan tiruan yang dihasilkan menjadi padat dan memiliki permukaan yang realtif lebih rata. Bentuk plat tekan ini diperlihatkan pada gambar 4.

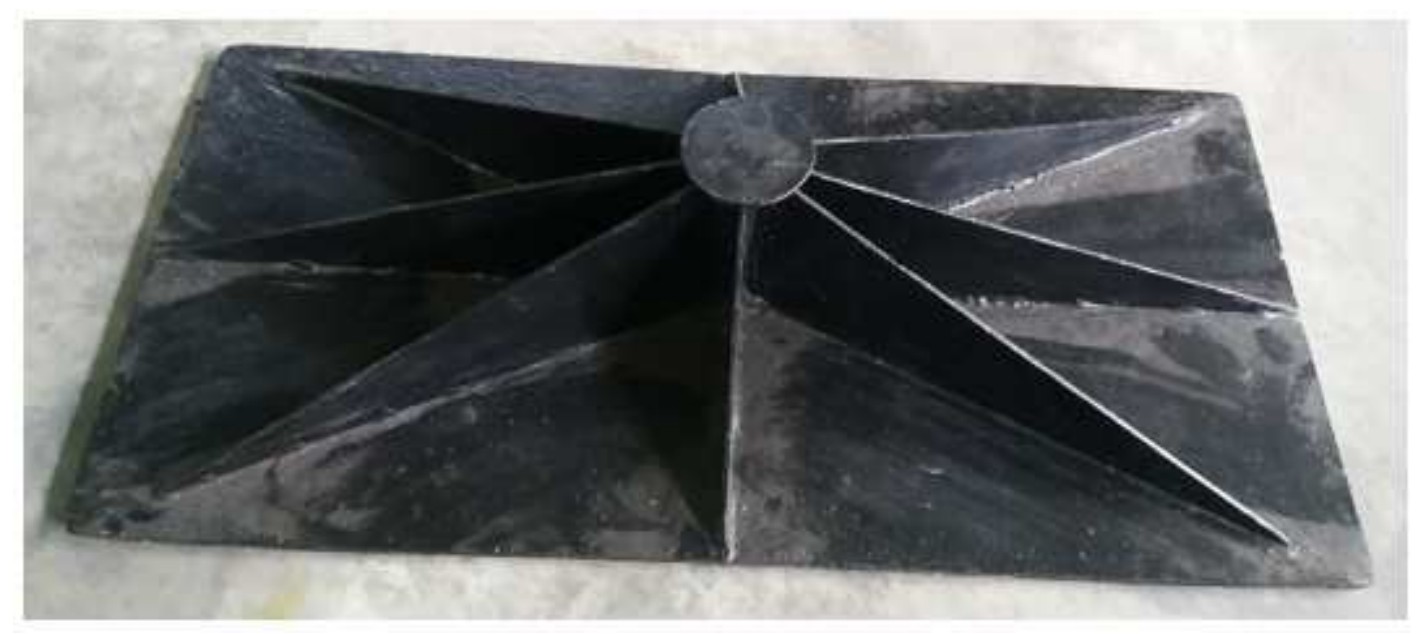

Gambar 4. Bagian pemadatan bahan baku (plat tekan)

Bentuk sirip yang digunakan bertujuan untuk menghindari terjadinya konsentrasi tegangan pada salah satu bagian plat tekan tersebut. Gaya yang diberikan didistribusikan relatif lebih merata pada seluruh bagian plat tekan. Dengan demikian dapat dihasilkan bentuk permukaan kayu tiruan yang lebih rata.

Analisa gaya $\mathrm{F}$ pada bagian pemadatan bahan (plat tekan) diilustrasikan pada gambar 5. Gaya yang diterima dari ujung titik B selanjutnya akan menekan plat tekan dan selanjunya tekanan akan didistribusikan plat tekan ke spesimen atau benda kerja.

$$
\mathbf{F}=2725,174 \mathrm{~N}
$$

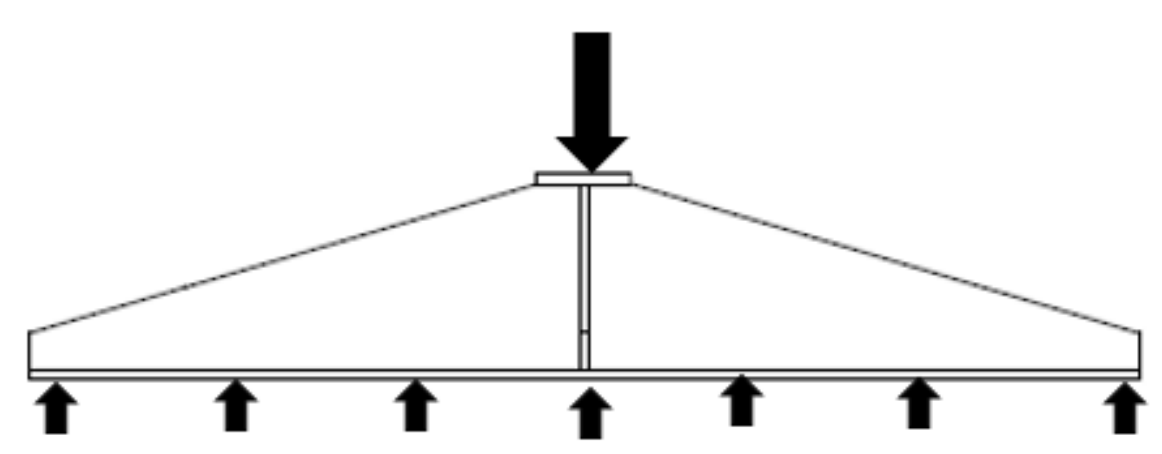

Gambar 5. Distribusi tekanan pada plat tekan 
Diasumsikan gaya dari dongkrak botol pada $\mathrm{FA}=1362,587 \mathrm{~N}$, dengan demikian gaya reaksi pada titik B pada gambar 3 ialah sebesar 2725,174 N. Jarak antara titik B ke tumpuan $\mathrm{C}$ adalah $\mathrm{L}=200 \mathrm{~mm}$. Dengan demikian gaya $\mathrm{F}$ yang bekerja pada bagian pemadatan bahan (Plat tekan) adalah $13,625 \mathrm{~N} / \mathrm{mm}$.

Struktur penyangga dan pin ini berfungsi sebagai tumpuan batang penekan dalam meneruskan gaya dari alat pembangkit beban (hidrolik minyak) hingga akhirnya tekanan didistribusikan oleh plat tekan, selain itu struktur penyangga juga berfungsi sebagai dudukan pembangkit beban (hidrolik minyak). Struktur penyangga dan pin ini diperlihatkan pada gambar 6. Analisa gaya $\mathrm{F}$ pada stuktur penyangga dan pin diilustrasikan pada gambar 7 .

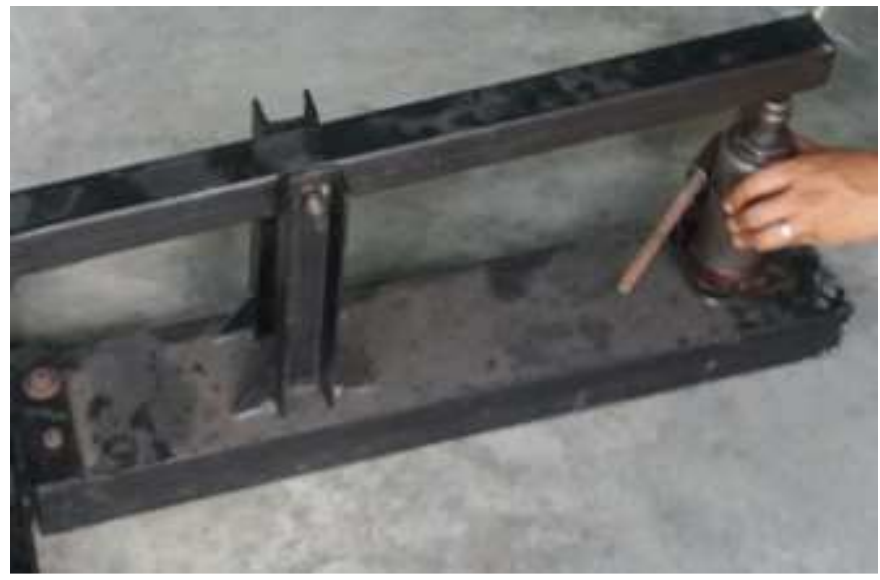

Gambar 6. Struktur penyangga dan Pin

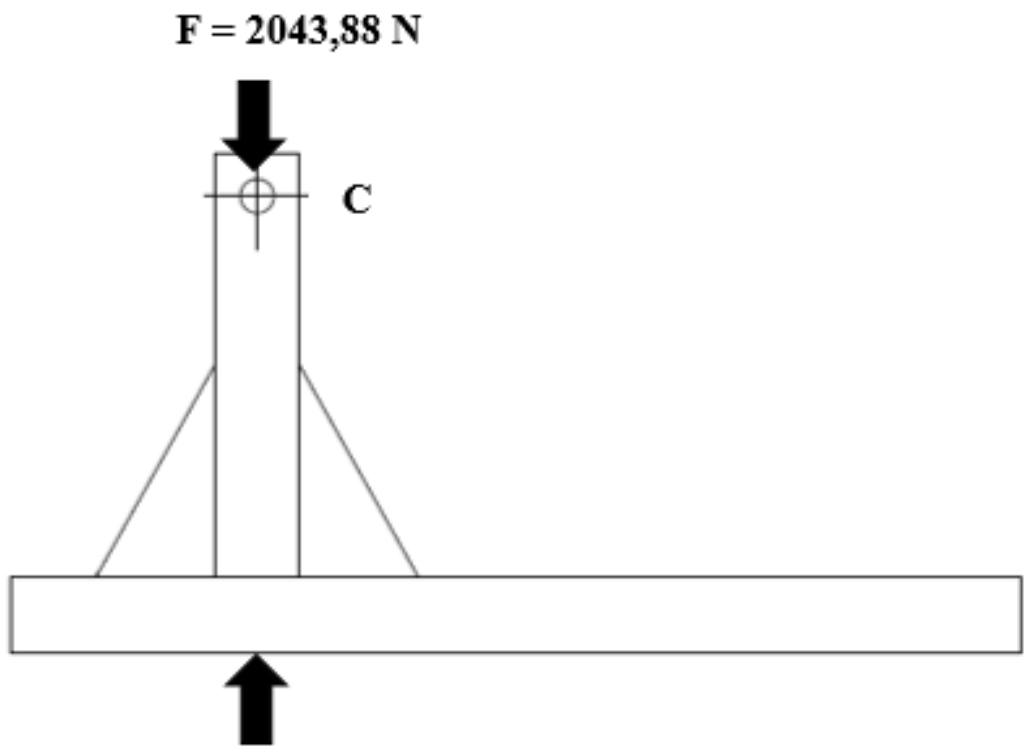

Gambar 7. Analisa gaya pada struktur penyangga dan pin

Analisa gaya $\mathrm{F}$ pada bagian pin dengan asumsi jumlah momen pada titik $\mathrm{A}=0$, maka gaya F yang bekerja pada titik C (Pin) adalah 2043,88 N. Beban tekan yang dibutuhkan untuk menekan plat penekan cetakan diperoleh dari gerak angkat alat hidrolik. Tekanan 
yang diberikan pada zat cair dalam ruang tertutup akan diteruskan sama besar ke segala arah (Hukum Pascal) sebesar gaya F2 adalah 1362,587 Newton.

Hasil cetakan alat ini ialah berupa papan tiruan yang terbuat dari bahan komposit laminate diperkuat lembaran batang pisang. Hasil cetakan tersebut diperlihatkan pada gambar 8. Berdasarkan hasil uji coba pencetakan spesimen tersebut terlihat bahwa bentuk papan yang dihasilkan sudah menyerupai bentuk papan kayu komersial, meski masih butuh penelitian lanjutan untuk menghasilkan bentuk yang lebih baik lagi. Morfologi bentuk papan tiruan secara visual dijelaskan pada tabel 1.

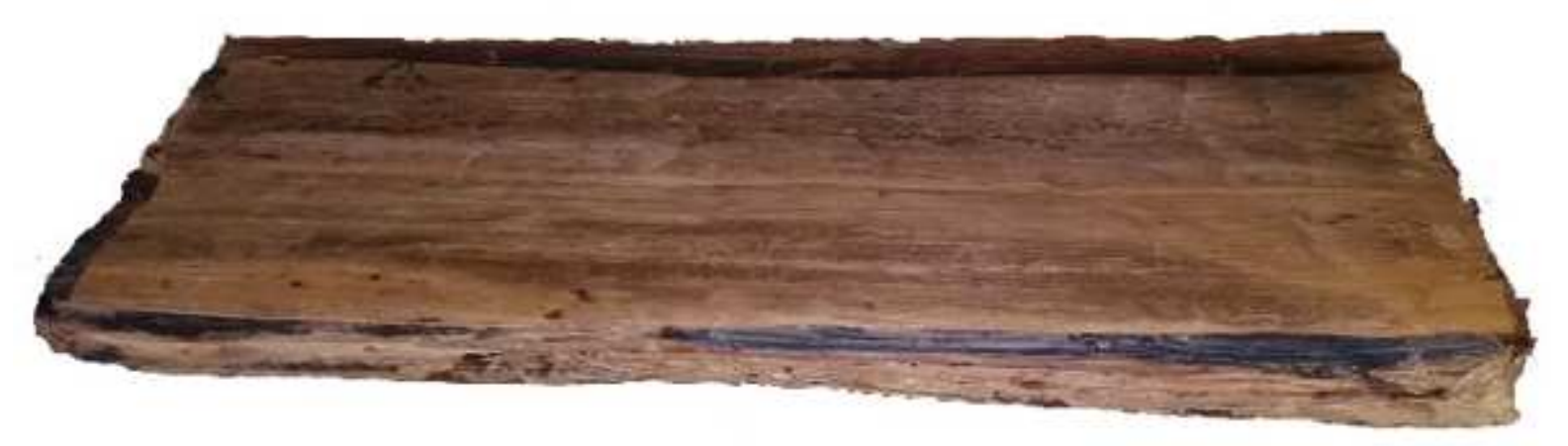

Gambar 8. Spesimen hasil cetakan

Tabel 1. Morfologi papan tiruan dari bahan pisang

\begin{tabular}{|c|c|c|c|}
\hline No. & Karakteristik & Bentuk secara visual & Keterangan \\
\hline 1. & Bentuk dan Ukuran & $\begin{array}{l}\text { Sudah menyerupai papan kayu komersial. } \\
\text { Terjadi penambahan ketebalan hingga } 10 \\
\text { mm dari bentuk dan ukuran semula setelah } \\
\text { dibiarkan } 2 \text { jam (ketika dikeluarkan dari } \\
\text { cetakan). }\end{array}$ & \\
\hline 2. & Permukaan & $\begin{array}{l}\text { Relatif sudah rata tapi masih kasar. } \\
\text { Permukaan lembut (elastis), dan terdapat } \\
\text { beberapa bagian lapisan yang terkelupas. }\end{array}$ & \\
\hline 3. & $\mathrm{Bau}$ & $\begin{array}{l}\text { Bau daun pisang kering, tetapi tidak } \\
\text { menyengat. }\end{array}$ & \\
\hline 4. & Warna & $\begin{array}{l}\text { Coklat muda dengan corak bintik-bintik } \\
\text { horizontal kehitaman. }\end{array}$ & \\
\hline 5. & Berat Jenis & $\begin{array}{l}\text { B.J. rata-rata kayu tiruan ialah } 410 \mathrm{~kg} / \mathrm{m}^{3} \text {. } \\
\text { Lebih ringan sedikit dengan B.J. kayu profil } \\
\text { komersial, yaitu rata-rata } 500 \mathrm{~kg} / \mathrm{m}^{3} \text {. }\end{array}$ & \\
\hline
\end{tabular}

\section{KESIMPULAN}

Hasil penelitian ini berupa alat cetak untuk pembuatan kayu tiruan dari bahan komposit laminate batang pisang. Berdasarkan penelitian yang telah dilakukan diperoleh kesimpulan sebagai berikut: (a) Desain alat cetak kayu tiruan telah dilakukan dengan menggunakan metode analisa statika struktur. Bentuk wadah/tempat pembuatan papan 
tiruan ialah balok dengan panjang $500 \mathrm{~mm}$, lebar $200 \mathrm{~mm}$, dan tebal $20 \mathrm{~mm}$. Gaya yang dibutuhkan alat untuk menekan plat tekan diperoleh dari daya dorong alat hidraulik. Agar besarnya gaya yang dihasilkan menjadi dua kali lipat dari yang diberikan, berdasarkan perhitungan analisa yang telah dilakukan, maka panjang ujung lengan penekan ke tumpuan lengan tekan adalah $400 \mathrm{~mm}$ dan ujung yang ditekan ke titik tumpuan lengan tekan ialah $200 \mathrm{~mm}$. Panjang horizontal keseluruhan lengan tekan ialah $600 \mathrm{~mm}$. (b) Alat cetak kayu tiruan telah dibangun dengan bentuk diperlihatkan pada gambar 4.6. Alat ini terbuat dari bahan baja St. 35. Pemilihan bahan ini dikarenakan alat yang dibentuk akan mengalami tekanan selama proses pencetakan kayu tiruan. Berat kesluruhan alat ialah 50 $\mathrm{kg}$.

\section{UCAPAN TERIMAKASIH}

Terima kasih yang sebesar-besarnya kepada Jurusan Teknik Mesin, Fakultas Teknologi Industri, Institut Teknologi Medan yang telah memfasilitasi penyelidikan ini hingga selesai.

\section{REFERENSI}

[1] Y. Rahayu, Statistik Bidang Planologi Kehutanan dan Tata Lingkungan Tahun 2016, Jakarta: Kementrian Pertanian Republik Indonesia, 2017.

[2] D. Chrisendo, V. V. Krishna and H. Siregar, "Land-use change, nutrition , and gender roles in Indonesian farm households," Forest Policy and Economics Journal, vol. 118, p. 1-11, 2019.

[3] T. Puspitojati, M. Y. Mile and E. Fauziah, Hutan Rakyat Sumbangsih Masyarakat Pedesaan Untuk Hutan Tanaman, Jakarta: PT. Kanisius, 2014.

[4] A. R. H. Bisjoe, A. K. Wakka and N. Hayati, Kemitraan Pengelolaan Hutan Rakyat: Pembelajaran dari Bulukumba, Makassar: Kementrian Kehutanan Republik Indonesia, 2016.

[5] B. A. Margono, P. V. Potapov, S. Turubanova, F. Stolle and M. C. Hansen, "Primary forest cover loss in Indonesia over 2000 - 2012," Journal of Foerstry, vol. 112, pp. 1-15, 2017.

[6] A. A. Susanti, Outlook Komoditi Pisang, Jakarta: Sekretariat Jenderal Kementerian Pertanian, 2014.

[7] B. Harpini, Komoditas Ekspor Indonesia, Jakarta: Kementerian Pertanian Republik Indonesia, 2017.

[8] A. Kuczumow, J. Nowak and R. Kuzioła, "Analysis of the composition and minerals diagrams determination of petrified wood," Microchemicals Journal, vol. 148, p. 120-129, 2019.

[9] E. J. Barbero, Introduction to Composite Materials Design, New York: CRC Press, 2018.

[10] A. Padanattil, J. Karingamanna and K. M. Mini, "Novel hybrid composites based on glass and sisal fiber for retrofitting of reinforced concrete structures," Construction Building Materials, vol. 133, p. 146-153, 2017.

[11] M. Yuhazri, A. Zulfikar and A. Ginting, "Fiber Reinforced Polymer Composite as a Strengthening of Concrete Structures: A Review," in 2nd International Conference in Industry and Manufacture Engineering, Medan, 2020.

[12] K. L. Pickering, M. G. A. Efendy and T. M. Le, "A review of recent developments in natural fibre composites and their mechanical performance," Composite Part A, vol. 83, p. 98-112, 2016.

[13] B. Xu and H. Y. Li, Advanced Composite Materials and Manufacturing Engineering, Beijing: Trans Tech Publications Ltd, 2012.

[14] B. Benhabib, Manufacturing, Design, Production, Automation, and Integration, New York: Marcel Dekker, 2003.

[15] S. S. Kumar and V. Anbumalar, "Selection and Evaluation of Natural Fibers - A Literature Review," Composite Part A, vol. 18, p. 929-939, 2015. 
[16] A. Lotfi, H. Li and D. V. Dao, "Natural fiber-reinforced composites: A review on material, manufacturing, and machinability," Journal of Thermoplastic Composite Materials, vol. 5, pp. 1-47, 2019.

[17] A. J. Zulfikar, "The Flexural Strength of Artificial Laminate Composite Boards made from Banana Stems," Budapest International Research in Exact Sciences (BirEx) Journal, vol. 2, no. 3, pp. 334-340, 2020.

[18] A. J. Zulfikar, B. Umroh and M. Y. R. Siahaan, "Design and manufacture of skateboard from banana stem," JMEMME (Journal of Mechanical Enggineering, Manufactures, Materials and Energy), vol. 3, no. 2, pp. 109-116, 2019.

[19] A. J. Zulfikar, B. Umroh and M. Y. Siahaan, "Investigation of Mechanical Behavior of Polymeric Foam Materials Reinforced by Oil Palm Empty Fruit Bunches (OPEFB) Fibers Due to Static and Dynamic Loads," JMEMME, vol. 3, no. 1, pp. 10-19, 2019.

[20] A. Rahmansyah and A. Zulfikar, "Manufacture of Water Pipe From Clampshell Powder Materials," JMEMME (JOURNAL OF MECHANICAL ENGINEERING, MANUFACTURES, MATERIALS AND ENERGY), vol. 2, no. 2, pp. 73-77, 2018.

[21] A. Zulfikar and G. Harahap, "Numerical Analysis of Polymer Foam Composite Material (PFCM) Reinforced by Palm Empty Bunch Fiber (PEBF) at Fracture Point Due to High Strain Impact Load," Budapest International Research in Exact Sciences (BirEx) Journal, vol. 2, no. 1, pp. 86-95, 2020.

[22] Zulfikar and Misdawati, "Manufacture of mold of polymeric composite water pipe reinforced charcoal," in Friendly City 4 International Conference, Medan, 2018.

[23] A. J. Zulfikar, A. Sofyan and M. Y. Siahaan, "Numerical Simulation on The Onion Dryer Frame Capacity of $5 \mathrm{~kg} /$ hour," JMEMME (Journal of Mechanical Engineering Manufactures Materials and Energy), vol. 2, no. 2, p. 86-92, 2018.

[24] A. Zulfikar and Z. Arief, "Kekuatan Tekan Parking Bumper Trapesium Dimodifikasi (PBTD) Berbahan Serat Tandan Kosong Kelapa Sawit," Mekintek, vol. 6, no. 2, pp. 423-428, 2015.

[25] A. Zulfikar, "Desain Cetakan Pipa Air Komposit Polimer Arang Kayu," in Seminar Nasional Teknologi dan Rekayasa (SNTR 2016), Tapak Tuan, 2016.

[26] A. Zulfikar, "ANALISA EKSPERIMENTAL MODULUS ELASTISITAS BAHAN KOMPOSIT GLASS FIBER REINFORCED PLASTIC (GFRP) BERDASARKAN VARIASI DIAMETER SERAT AKIBAT BEBAN IMPAK LAJU REGANGAN TINGGI EXPERIMENTAL ANALYSIS OF MODULUS ELASTICITY GLASS," JMEMME (Journal of Mechanical Engineering, Manufactures, Materials and Energy), vol. 1, no. 2, pp. 47-56, 2017. 